\title{
Stratospheric Electric-Field Measurements Before and After Lightning Events
}

\author{
M.M.F. Saba \\ O. Pinto Jr. \\ I.R.C.A. Pinto \\ R.B.B. Gin \\ O. Mendes Jr.
}

Instituto Nacional de Pesquisas Espaciais - INPE

\begin{abstract}
Stratospheric vertical electric-field measurements associated with an isolated thunderstorm were obtained during a balloon flight launched in Cachoeira Paulista, Brazil, on 23 March 1995. The behavior of the vertical electric-field before and after large cloud-toground positive lightning flashes is discussed and attributed to the existence of static and transient shielding layers around the thunderstorm. The data just after the flashes can be explained by assuming a static shielding layer around the thunderstorm correspondent to a decrease in the conductivity inside the cloud by a factor of three or more. The data before the first lightning flash can be explained by assuming a transient shielding layer just above the top of the thunderstorm, produced by the near breakdown field inside the cloud.
\end{abstract}

\section{INTRODUCTION}

Stratospheric vertical electric-field measurements associated with thunderstorms and lightning flashes have been published by several authors (e.g. Holzworth and Chiu, 1988; Pinto et al., 1992). The vertical electric-field associated with thunderstorms is characterized by an inversion with respect to the fair-weather field. The vertical electricfield associated with lightning flashes have a signature typical of a sferic, with a recovery curve which depends on the local conductivity and the internal processes inside the thunderstorm. In most lightning events recorded in the literature, the field not show any disturbance previous to the sferic occurrence, and just before and after the sferic have the same intensity.

In this paper the electric-field data obtained during a period associated with two large positive flashes produced by an isolated thunderstorm are presented. The data were obtained during a balloon flight launched from Cachoeira Paulista, Brazil $\left(22^{\circ} 44^{\prime}\right.$ S, $44^{\circ} 56^{\prime} \mathrm{W}$ ) on March 23, 1995. The thunderstorm characteristics was measured by a meteorological radar.

\section{RESULTS}

Figure 1 shows a 8 -min interval of stratospheric vertical electric-field data obtained during the balloon flight in an altitude of $32.2 \mathrm{~km}$. Two positive cloud-to-ground flashes indicated by $\mathrm{P} 1$ and P2 and a third flash (cloud-to-ground or intracloud flash), originated in the same isolated thunderstorm, can be seen in the figure. The electric-field before the first flash (P1) shows an abrupt increase which correspond to $0.28 \mathrm{~V} / \mathrm{m}$. The increase remains for about 4.5 minutes. After the positive flashes $\mathrm{P} 1$ and $\mathrm{P} 2$, the field recovery to the previous value in a few seconds. The identification of the first two flashes as positive flashes is discussed in Saba et al. (1997).

\section{DisCUSSION AND CONCLUSIONS}

It is interesting to note that even after large positive flashes, the vertical field return to the same previous value. It means that the charge discharged by the flashes should be very small compared with the total charge associated with the thunderstorm. Assuming that it is the case, we have calculated the charge discharged by the positive flashes using the coulomb law, since the duration of the flash is very small compared with the relaxation time at balloon altitudes (a few seconds). In the calculation the positive charge inside the cloud was supposed to be located in 7 $\mathrm{km}$, considering that the top of the cloud was estimated by the radar to be around $8 \mathrm{~km}$. For both positive flashes in figure 1, we have obtained a charge of about $16.4 \mathrm{C}$. Such a charge should produce a decrease of about $0.43 \mathrm{~V} / \mathrm{m}$ in the vertical field. Since this decrease was not observed, and considering that the vertical electric-field resolution of our measurements is 0.15 $\mathrm{V} / \mathrm{m}$, we can estimated the shielding factor associated with the screening layer around the thunderstorm. The calculation now should consider the gradient of the atmospheric conductivity with the altitude. Following the work of Pinto et al. (1988) we have found that a factor of three or more is necessary to explain our observations. Such a factor relates the effective charge as measured by an observer outside the cloud with the real charge inside the cloud. We can see that the effective charge is only a fraction of the real charge inside the cloud. Considering that this factor also relates the conductivity inside and outside the thunderstorm (Volland, 1984), we found that the conductivity inside the cloud is lower than that outside by a factor of three or more. This value is in reasonable agreement with the values reported in the literature (e.g. Volland, 1984).

The abrupt increase in the electric field prior to the first positive flash is of about $0.28 \mathrm{~V} / \mathrm{m}$. This 
increase remains for about 4.5 minutes. We suggest that this-increase is related to a transient shielding layer just above the cloud, produced in consequence of the large breakdown field which is expected to exist inside the cloud just before a cloud-to-ground lightning event. The time necessary to a transient shielding layer to be completely shielded $(99 \%)$ by the atmospheric charges was estimated by Brown et al. (1971) and Marshall and Lin (1992) as equal to five times the relaxation time constant at the shielding layer altitude. Considering the altitude of the top of the cloud as this altitude, we obtain 4.4 minutes to complete shielding. This value is very close to the value of 4.5 minutes indicated in figure 1 , as the time duration of the increase of 0.28 $\mathrm{V} / \mathrm{m}$. A similar case (with intensity of about $0.3 \mathrm{~V} / \mathrm{m}$ ) seems to have been observed by Holzworth and Chiu (1982).

\section{ACKNOWLEDGMENTS.}

The authors would like to thank the Fundação de Amparo à Pesquisa do Estado de São Paulo (FAPESP) for supporting through the project 92/4774-2.

\section{REFERENCES}

Brown, K.A.; Krehbiel, P.R.; Moore, C.B.; Sargent, G.N. Electrical screening layers around charged clouds. Journal of Geophysical Research, 76:2825-2835, 1971.
Holzworth, R.H.; Chiu, Y. T. Sferics in the stratosphere. In: Volland, H., ed. Handbook of Atmospherics. Florida, CRC, 1982, v.2.

Marshall, T.C.; Lin, B. Electricity in Dying Thunderstorms. Journal of Geophysical Research, 97: 9913-9918, 1992.

Pinto, I.R.C.A.; Pinto Jr., O.; Gonzalez, W.D.; Dutra, S.L.G.; Wygant, J.; Mozer, F.S. Stratospheric electric field and conductivity measurements over electrified convective clouds in the South American region, Journal of Geophysical Research, 93(D1):709-715, 1988.

Pinto, I.R.C.A.; Pinto Jr., O.; Gin, R.B.B.; Diniz, J.H.; Carvalho, A.M. A coordinated study of a storm over the South American continent: 2. Lightning- related data, Journal of Geophysical Research, 97(D16): 1820518213, 1992.

Saba, M.M.F.; Pinto Jr., O.; Pinto, I.R.C.A.; Gin, R.B.B.; Mendes Jr., O. Stratospheric balloon measurements of sferics in Brazil, in this issue.

Volland, H. Atmospheric Electrodynamics. New York, N.Y., Springer Verlag, 1984.

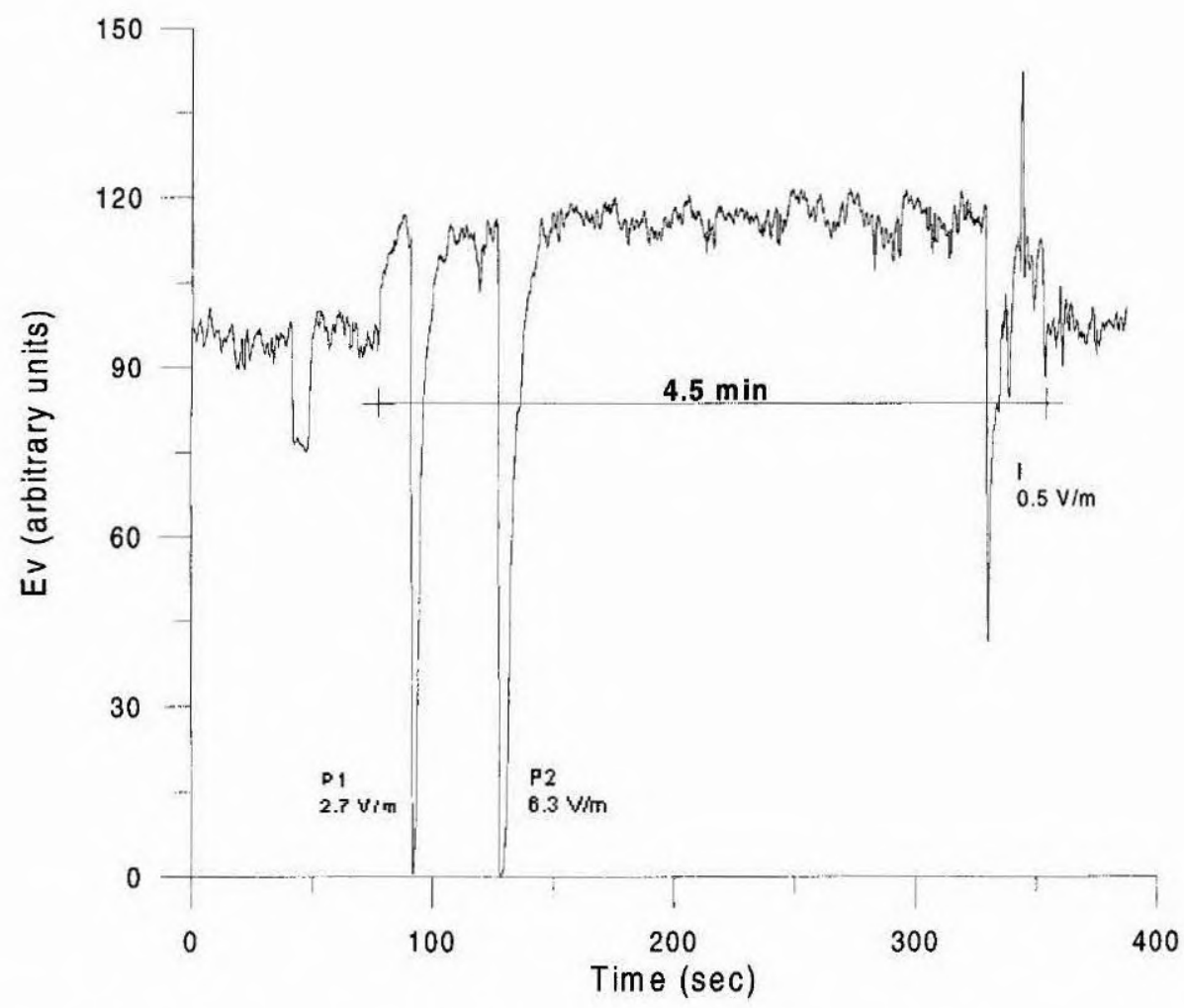

Fig. 1 - Vertical electric-field data obtained on March 23, 1995. The drop around $50 \mathrm{sec}$ is due to a conductivity measurement. 